\title{
The Online Business Model of Individual Customization Accessories
}

\author{
Y.Yu \\ DonghuaUniversity, China
}

\author{
H.Y. Ru \\ Donghua University, China
}

\author{
Y.J. Tian \\ Donghua University, China
}

\begin{abstract}
This article focuses on online business model of individual customization accessories.Though analyzing several online shopping website to find the advantages and disadvantages of the business model nowadays. Though analyzing the customers` need to find the blank parts of market and find the affection about sales quantity from composition of every factor. In this paper, we mainly use theoretical analysis, descriptive Statistics, interdisciplinary cross-analysis, market research analysis, and other methods in the design discipline. The new and original of this paper is trying to give a new improved business model of individual customization of accessories that may meet the requirements of the customers in the future.
\end{abstract}

Keywords-online shopping; accessories; customization; business model

\section{INTRODUCTION}

\section{A. The Developing of E-Business}

Since 1997, online shopping becomes more and more popular and engages high attention of costumers for its simple, fast, low-cost advantages.Until December 2013, China's online shopping users' scale up to 302 million people, the online shopping utilization rate rise to $48.9 \%$. Compared with 2012, online usersincreased by 59.87 million people, the growth rate is $24.7 \%$ [1].TheWell-known research institutions Forrester a prediction research report says that next year the number of online consumers of China may reach 356 million, even more than the total population of America.

With the development of economy and society, more and more people begin to pursue high quality and personalized life style.They want individual customization products more than ever. As mass-produced is the business organization principle of the century,individual customization will be the future.

\section{CURRENT SITUATION}

\section{A. The Traditional Customization}

The traditional customization means design and produce one product for a customer to meet his need.Includinghaute couture, shoes, bags, jewelries and Chinas.Some luxury brands such as ChristianDior, Valentino, Armani are famous for itshandmade luxury goods. But at present, the high-level customization is niche industry; For example, even big brand can only produce less than 3000 pairs of shoes a year. This handmade shoe need customer to visit the studio,shoemaker will measure their foot and do the cutting and stitching in accordance with the dimension of foot. It costs a lot of time and money to make a quitecomfortable shoe.

\section{B. Summary of Online Business Models of Customization}

Individual customization is a new arisen manufacturing and marketing mode that applies the information technology and network technology. Consumersplay a much greaterrole during making products. The merchant'soffers diversified basic goods for customers to choose.And give them choice to design the products based on private demand and aesthetic.

\section{Current Situation of Network Customization for Accessories Products}

In all parts of the nation, many accessories enterprisesbeginthe new mode of sale online.Individual customization has fast growth on the global commodity markets inrecent years. The sale online mode is helpful to the individual requirement of consumers and very appropriate for the individual consumer market for it can satisfy the individual demands of a certain consumer in a very short time. IDX website,for example, there are variety of products can be customized. There are women`s shoes, men`s shoes, children`s shoe, all kinds of hats and even electronic products. It provides much more choice to meet the customers` need. Thecustomization process of IDX is shown in Figure I and Figure II .

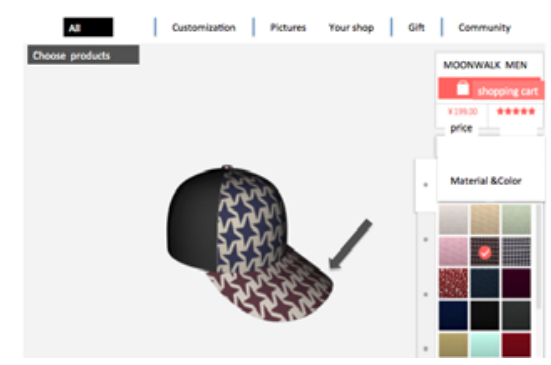

FIGUREI. IDX CUSTOMIZE PROCESS-HAT. 


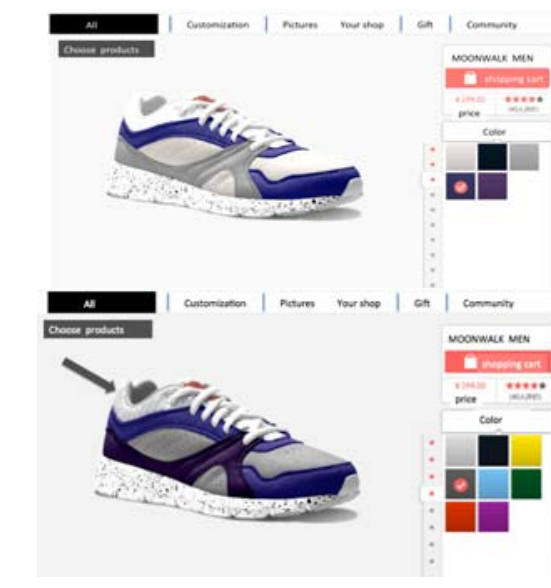

FIGURE II. IDX CUSTOMIZE PROCESS-SHOES.

\section{Disadvantages of Online Customization for Accessories Products}

Currently, customers can only make decision for the material, color and pattern on the online customization. Without measuring the body shapes, this kind of customization is actually not individual customization for accessories products in essence. Just recombine the material; color and pattern based on the original accessories style that the company already designssucceed. But measuring the foot is the most important process for customized accessories. It is vital that body are measured and fitted so that their accessoriesfit the curves perfectly to keep comfortable and healthy.

\section{THE TREND OF AN INDIVIDUAL CUSTOMIZATION}

Accessories products individuation incorporates two aspects: one aspect is sensory psychological individuation originating from different tastes and different living environment of accessoriesconsumers [2]. Sensory demands mainly include the demands in sculpt, color, tactile sensation and so forth, namely the demands in style and texture. Another aspect is product function individuation originating from different body shapes and different wearing habits of accessories customers. Function demands mainly include the demands in structure, shape, material and so forth, namely the demands in truss and fitness.

Accessoriesproducts have certainspecificity, each people have different shape of body curves, and even some subtle differences may cause physical discomfort. Soit is the inevitable trend of development that customizesaccessories for different body.

\section{A. The Currently Onlinecustomization Lay the Foundation}

The currently online customization laid the foundation for future. It opens the market to customers nationally and internationally. Costumers accept more service like measuringthe feet to make a personal accessory that fit the body curves.

\section{B. People's Pursuit of Quality of Life}

A hand-making bespoke accessory is a status symbol to the famous stars, businessman and politician. For example
Ferragamo keen to star for the rest of the world production of shoes. From Marilyn Monroe to was the first Asian actress Zhang Ziyi and actor Tony Leung, tailor-made shoe [3]. However, except these people, more and more white collars and the others who pursue high quality life want customized accessories.Nowadays less and less people can afford spending too much time on shopping in theshoppingcenter or shops due to the fast-paced life. So it will capture the market if people can suffer the Internet to shop anytimeand anywhere.

\section{Huge Market Potential}

According to the China Leather Industry Association (CLIA) research service titled China accessories Markets in2014 provides an overview of the different vertical segments consuming accessories in china. The accumulated growth rate of accessories turned positive.

\section{Technology Development Support}

The development of high-tech and network technology have influenced our lifestyles and our way of thinking. Ecommerce is stealing market share from traditional retail and fast. The individual customization for accessories products based on the network is just around the corner [4].

Currently, 3D printing systems are more and more popular using in the fashion products developing. Catherine Waleswho is a London designer showing a series of accessories making by 3D Printing. These artworks amazed the customers. The 3D accessories are shown in Figure III-IV.As soon as the time needed for the printing process drops to minutes not hours, and as equipment becomes cheap enough to purchase on a wide scale, 3D-printed accessories will become more and more ubiquitous. With the current pace of technical progress, we would expect 3D-printed accessories to be a reality within the decade. They re already off to a flying start.

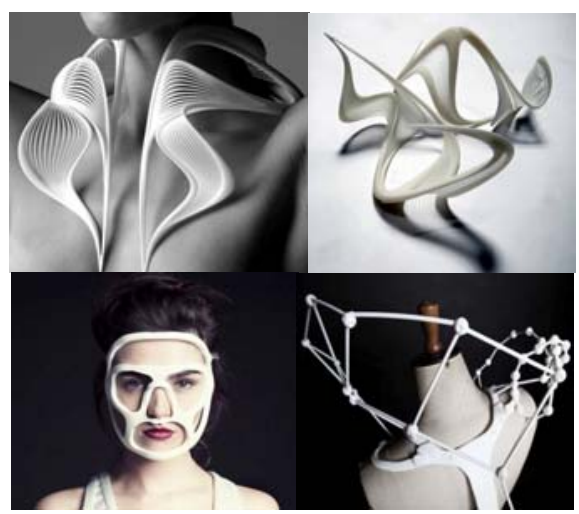

FIGURE III-IV. "PROJECT DNA”3D ACCESSORIES BY CATHERINE WALES.

\section{The Prediction of The Business Model}

ThemoderninformationtechnologyrepresentedbytheInterne thasoffereda favorableenvironmentfor network customization for accessories products.In the future, network customization will be widely used. Firstly, customer can use a smart-phone application to scan the shape of body such as feet, neck arm and so on. Secondly, the 1:1 model of ones body part will be made by 3 Printing machine and the accessoriesshape will be 
produced by traditional machine based on the data of body. The finished products are delivered to them by mail or by a delivery service.

From a business perspective, many benefits will flow from this process: zero inventory, lower transport costs, reduce labor costs and can produce perfectly what they want according to customer` requirements [5].

From a consumer perspective, the 3D accessoriesthe data of ones body curves will be saved in the database and continuously used. And using it to make one`s accessories will very fit bodycurves. Morecomfortable, healthy and elegant that reflects their personality and high standard of living.

The function module diagram of this individual customization business model for accessories products online is shown in Figure $\mathrm{V}$ every module realize the functions as follows:

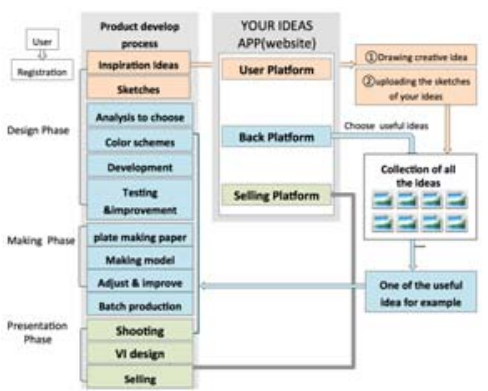

FIGURE V.ONLINE BUSINESS MODEL FOR INDIVIDUAL CUSTOMIZATIONACCESSORIES.

\section{V.CONCLUSION}

Online customization foraccessories is closely related to personal life. It is an important direction for the development of accessories manufacturing in the future. It will broaden the individual customization market rates with the support of network. The individual customization for accessories is very helpful for personal health. This accords with the aspirations of the high quality life. Thus the individual customization for accessories online has huge market prospects.

The paper proposes a trend of an individual customization business model for accessories products based on network and uses the technology of 3D Printing, scan application. The users can not only obtain professional advice for accessories products choosing but also gain users' satisfaction in appearance and comfort aspect of customization accessories products by using this system platform. At the same time, this individual customization system for accessories products can shorten the periods of design and manufacture, reduce costs and enhance competition power of enterprises.

\section{ACKNOWLEDGEMENT}

The programs of shanghai universities technology platform-Donoghue university shanghai style fashion design and value creationcenter.

\section{REFERENCES}

[1] Martin G. Helabder, Jianxin Jiao. Research on E-product development (ePD) for mass customization. Technovation, 2002, (22): 717-724

[2] PengPiao-lin, Lin Zhen-hua, Meng Qing-hai. New Model of Channel of Shoes Sale, Leather Science and Engineering, 2004,14 (4): 47-49

[3] GaoChao,LiJiao,Guo Yong-cai. Local Deformation Technique in Shoe LastModeling. Journal of Computer- Aided Design \& Computer Graphics, 2002,14(9): 890 893

[4] Wahba, M. A., \&Bridwell, L. G. Maslow reconsidered: A review of research on the need hierarchy theory : Organizational Behavior and Human Performance , 1976 : 212-240.

[5] Kai Shi\&Dajuan Fan, An Individual Customization System for Shoe Products Based on the Network, Zhejiang Industry and Trade Polytechnic, Wenzhou, P. R. China. 